\title{
School librarians coping with electronic environment
}

\author{
Jadranka Lasic-Lazic \\ Full professor \\ University of Zagreb, Faculty of Humanities and Social Sciences \\ Department of Information Sciences, Croatia \\ Mihaela Banek Zorica \\ Assistant professor \\ University of Zagreb, Faculty of Humanities and Social Sciences \\ Department of Information Sciences, Croatia \\ Sonja Spiranec \\ Assistant professor \\ University of Zagreb, Faculty of Humanities and Social Sciences \\ Department of Information Sciences, Croatia
}

\begin{abstract}
Paper focuses on abilities of librarians to adapt and respond to the constantly emerging changes influenced by the advancement of ICT. The authors emphasize the necessity of defining and promoting new concept and understanding of the school library in electronic environment. Traditional school library roles need to adapt and change to respond to the needs of new users growing up in the interactive and information overloaded environment. Many of the aspects of current school library tasks and roles originate from a print-based culture which is incongruent with the transient and hybrid nature of digital environments. These radically changing environments are posing different tasks on school librarians leading them to balance carefully between the traditional school environments, infrastructure, institutions hierarchy and with the various new needs of "Google generation" users. Taking into account all the changes in the information environment authors emphasise the necessary improvements in education of school librarians.
\end{abstract}

Keywords: Web 2.0, School library 2.0, curriculum

\section{Change in the information space}

Since its development and inception, ICT has changed every facet of human existence and established itself as a part of the fabric in social and economic enterprises as well as in entertainment, education, culture etc. Services offered at first where purely focused on the presentation of the respective institutions, their contents and services, in a mainly static manner and one-directional in nature. Users where supplied with information from the web, making them largely consumers of information resources that were delivered to them through so called Web 1.0 environment. This type of communication and search of information was largely satisfying, even fascinating for this first generation of web users or digital immigrants who where not born to the digital world, but have had to learn how to cope with it.

When the generation of digital natives emerged the time was ripe for entering a new, more social and participatory phase of the Web, denoted as Web 2.0. Digital natives have 
grown up around instantly accessible information and within a networked culture, in crossfire of multimedia stimuli, which resulted in the development of cognitive thinking patterns, expectations and methods of deriving meaning that differ from previous generations. With this new generation, the educational environment together with the school and academic librarians has received new user, which motivated educational institutions to transform their Web 1.0 capacities and dive into the Web 2.0 world. To improve communication with their users and respond to their new needs libraries are exploring the vast Web environment and its Web 2.0 tools and services like wikies, blogs, RSS, mash- ups, and social networks like Facebook. One of the advantages of the Web 2.0 tools in library environment is that it can enhance the conversation of the library with the public, i.e. school library with its' users and get them involved in the planning and evaluation of library services, encourage sharing of knowledge, as well as to improve the overall experience of the users (Stephens and Collins, 2007). The use of the Web 2.0 tools may also better fulfil the expectations of the growing population of digital natives who "would want to create, remix and share content" (Titangos and Mason, 2009). With this transition to the socially oriented environment and the need to denote changes in the library environment the concept of Library 2.0 has emerged.

Although the above described concepts have realized the transformation of educational and information institutions from places of passive information consumption to dynamic, participative and creative knowledge production spaces, they still just partially offer a sense of ownership, are still relatively passive and flat in nature and therefore do not necessarily appeal to all types of users, especially those who are more attuned to 3D entertainment software and game based simulations. This explains the recent emergence of the new, 3.0 hype, focused on translating the 2.0 concepts to tangible, 3-dimensional social networking systems. (Keats and Smith, 2007) Those are characterized by rich, crossinstitutional, cross-cultural educational opportunities within which the learners themselves play a key role as creators of knowledge artefacts that are shared, and where social networking and social benefit outside the immediate scope of activity play a strong role. The distinction between artefacts, people and process becomes blurred, as do distinctions of space and time. These environments are still in their beginnings and although some of the educational institutions, as well as its libraries, have started exploring this new concept this still needs to be thoroughly explored. Still the fact that there is an emergence of the new subtype of the digitally born user - game based user has to be considered and new ways of coping with these types of users have to be explored and defined.

\section{How has ICT changed the users of school library}

Current developments and advancement of ICT demand a clear definition of position and importance of school library in electronic educational environment. Traditional library skills or information literacy needs to be adapted for managing through electronic environment. Personalization of educational process requires active involvement of all participants. Agile response to the need of "Google generation" and "Gamers generation" puts school librarians in difficult position but confirms their crucial role in educational process. In order to be active and knowledgeable citizens of 21 century students need do have a modern school library which acts as a pillar of the teaching and training in electronic environment. Knowledge is viewed as an important, or arguably the most important asset. Information and knowledge providers are still librarians although they constantly have to struggle with the, at first hand, easy use of the Internet or to be specific Google. Students today are used first try to find all the necessary information on the Google and in most cases instead of going to the library and receive information for reading and learning materials they 
rather spend in most cases more time search information via Google. Usually, they do not evaluating the sources found and take the ones that they think would satisfy their peers i.e. teacher.

A survey conducted by OCLC on user perceptions of libraries shows that the vast majority of those interviewed use search engines to begin an information search (84 percent). Only one percent begin an information search on a library Web site (p. 6-3), which doesn't mean that they are not interested in library services, but they may not discover those services if the library does not find a way to go to the user, rather than waiting for the user to come to the library. (Coyle, 2007.)

Rowley and Hartley (2008) argue that although Google as a brand has reached global popularity and usage by general public people still need do be informed and educated that there are numerous different information resources and principles of information retrieval. Furthermore, they present a comparative table of advantages and disadvantages of Google as an information tool.

\begin{tabular}{|l|l|}
\hline Advantages & Disadvantages \\
\hline Fast & $\begin{array}{l}\text { The user is not aware of the details of the } \\
\text { search that has been undertaken, and may } \\
\text { therefore have difficulty refining the search in } \\
\text { a meaningful way }\end{array}$ \\
\hline Simple keyword searching & $\begin{array}{l}\text { Irrelevant hits or missing of relevant sources } \\
\text { due to non-exploration of synonyms or related } \\
\text { terms, or to the definition of relationships } \\
\text { between words in search phrases }\end{array}$ \\
\hline $\begin{array}{l}\text { Underpinned by powerful search } \\
\text { technology that delivers highly relevant top } \\
\text { ten hits, from millions of websites and } \\
\text { documents }\end{array}$ & $\begin{array}{l}\text { It is difficult to distinguish between keywords } \\
\text { used as author and those used as subject (such } \\
\text { as "Shakespeare") without being able to } \\
\text { indicate field or data type }\end{array}$ \\
\hline $\begin{array}{l}\text { Simple search interface, which is the same } \\
\text { anywhere in the world (with language } \\
\text { changes as necessary) }\end{array}$ & $\begin{array}{l}\text { There can be as a sense that Google provides } \\
\text { too many hits, leaving it to the user to decide } \\
\text { on their cut-off point in scanning lists of hits. } \\
\text { Ranking of hits may not always show the best } \\
\text { sources for the searcher's query on the first } \\
\text { screen, and scanning several screens of hits is } \\
\text { tedious }\end{array}$ \\
\hline $\begin{array}{l}\text { Automatic spellchecking } \\
\text { Virtually always delivers something that is } \\
\text { relevant }\end{array}$ & $\begin{array}{l}\text { Relevant items may be scattered amongst } \\
\text { many other items; the onus is on the user to } \\
\text { evaluate and select }\end{array}$ \\
\hline $\begin{array}{l}\text { Pearches on a range of file formats (such as } \\
\text { access to the full text of documents or } \\
\text { websites }\end{array}$ & $\begin{array}{l}\text { Authority and quality of content of sources } \\
\text { varies, and the user needs skills and } \\
\text { judgement in selection }\end{array}$ \\
\hline
\end{tabular}

Figure 1. Advantages and disadvantages of Google usage (Rowley and Hartley, 2008)

Search engines such as Google are so easy and immediate that many young people, faced with a research assignment, just 'google' their way through the internet rather than struggle through the hoops of a more traditional library environment.(D. Loertscher, "The digital school library', Teacher Librarian, Vol. 30, No. 5, June 2003, p. 14.) This is exactly why information professionals i.e. school librarians must seriously get involved in educating 
their users information literacy and giving them insight in the context and principles of information space. More than ever students are left on their own with finding and evaluating vast number of information based in the electronic environment. Therefore it is necessary to teach them information literacy in order to make them fluent and knowledgeable in the net environment.

Most developed countries are concerned to develop and capitalize on their knowledge assets to generate wealthier societies and economic growth. In order to achieve this they focus on both the development of learning environments (schools, colleges, universities, workplaces, virtual learning environments) and the development of, and networked access to, knowledge resources. This central significance of knowledge means that it is important that a user has convenient and appropriate access to the best information or knowledge at the right time, and in the most appropriate format. In order to make this possible it is necessary to organize knowledge. (Rowley and Hartley, 2008.) The organization of knowledge in order to enable easier information retrieval is one of the librarians' tasks even before the emergence of the Internet. Nowadays, apart from organizing knowledge librarians need to educate their users to be information literate individuals meaning they need to know where and how to retrieve information, how to evaluate it, process, organize and present, as well as create knowledge.

Today's school library users want their information immediately, need only materials prescribed by the teacher and learn minimum required for passing the course. Majority is not even interested in additional materials and research, and do not want to invest additional time on learning. On the other hand, they are willing to spend enormous amount of time on-line connecting with their friends over the social networking systems like Facebook, Myspace, etc. Play various games, read large amounts of various information on the internet, not related to their educational topics (blogs, tutorials, wikis etc.), and in general spend huge amount of time by computer. Unfortunately, only a small amount of this time is dedicated to learning that will develop their skills and contribute their academic advancements.

Today's users have an expectation that they will find a community at their electronic destination. They also expect to interact with their information resources, not to consume them passively. (Coyle) The universe of information culture is changing fast and that libraries need to respond positively to these changes to provide resources and services that users need and want.

\section{School libraries and Web 2.0}

Traditional school library roles need to adapt and change to respond to the needs of new users growing up in the interactive and information overloaded environment. Many of the aspects of current school library tasks and roles originate from a print-based culture which is incongruent with the transient and hybrid nature of digital environments. These radically changing environments are posing different tasks on school librarians leading them to balance carefully between the traditional school environments, infrastructure, and institutions hierarchy as well as with the new needs of "Google generation” users.

School libraries and libraries in general are no more just a mere physical space that create and store large collections of print materials. Development of collaborative electronic environment and transformation of librarians from collectors of information to providers and mediators of information, and therewith knowledge, enables them to fully utilize their role as 
center of educational process. Extending their space to a virtual one using Web 2.0 technology could be one of the solutions to respond both to the students needs and help teachers in their teaching and learning.

Concept of Library 2.0 is based on four essential elements:

1. It is user-centered. Users participate in the creation of the content and services they view within the library's web-presence, OPAC, etc. The consumption and creation of content is dynamic, and thus the roles of librarian and user are not always clear.

2. It provides a multi-media experience. Both the collections and services of Library 2.0 contain video and audio components. While this is not often cited as a function of Library 2.0, it is here suggested that it should be.

3. It is socially rich. The library's web-presence includes users' presences. There are both synchronous (e.g. IM) and asynchronous (e.g. wikis) ways for users to communicate with one another and with librarians.

4. It is communally innovative. This is perhaps the single most important aspect of Library 2.0. It rests on the foundation of libraries as a community service, but understands that as communities change, libraries must not only change with them, they must allow users to change the library. It seeks to continually change its services, to find new ways to allow communities, not just individuals to seek, find, and utilize information. (Maness, 2006)

The variety of Web 2.0 tools opened a whole scale of possibilities and services that enable school librarians to offer modern and appealing services to their users. Moreover, the needs of these new generations can be compared with the traditional library principals libraries are for users and every user its' book. Within the new environment we can change only word book with the word "information" and the principle stays the same. If libraries are for users that they need to adapt to its users needs. Still one could not say that all the libraries are recognizing the modification of this rule and the importance of the new informational space and preferences of these new users.

Library 2.0 manifesto has created a lot of discussions and raised a lot of voices criticizing on it and the viewpoint than it presents. It is very enthusiastic and requires application of all the new services and changes that the modern times are bringing. Still, we do not need to be very critical and have to remember that regarding the web environment librarians were a bit slow (on a general level, not including individual initiatives) in involving in projects and responding to the changed information environment. This actually resulted in reinventing the wheel in knowledge organization in the electronic environment with the finding suitable solutions without asking the experts i.e. library professionals. Regarding the Manifesto we have to bare in mind that some of the hypothesis are a bit radical and have to be put in the right context. We have to address them with common senses and regard them as some sort of guidelines. Not everything is to be included in the school librarians program, tasks and objectives but still a lot of these thought should be considered. 
Like one of the statements „I will not fear Google or related services, but rather will take advantage of these services to benefit users while also providing excellent library services that users need." (Cohen, 2006) shows that we do not need to fear the new technology but have to embrace it, understand it and try to find the best way to help our users in dealing with the information in this „new“ information space. This can be applied for all the other services like wikipedia. In stead of banning things or saying that they are bad, we need to explain the benefits and disadvantages of certain services.

Among all the various library types only the majority of school libraries have embraced Web 2.0 technologies in their services for example to promote reading by creating book club blogs or sending announcements and discussions via podcatst. Usage of services like blogs, wikis and podcasts or audiocasts in school library can help both teachers and librarians especially if they work together. On one side school librarian supports educational process in promoting information literacy and enquiry based learning and on the other side helping teachers organize their teaching and learning material using Web 2.0 technology. One of the examples could be the usage of social bookmarking services (like deli.cio.us and diigo) which enables creation of joint collections but also promotes discussion and critical thinking by marking parts of the text (offered by diigo) and assigning students to discuss and evaluate information found. Only close collaboration of school librarians and teachers creates a successful learning environment that responds to the needs of the "Google generation".

\section{Educating the educators}

Recognition of current developments and trends in ICT and the emergence of Web 2.0 technologies as well as international trends that emphasize the importance to include the use of Web 2.0 technologies in library services and develop Web 2.0 training programs for librarians (Al-Fadhli, 2008) motivated us to apply changes in our curriculum. In order to enable and create successful school librarians educational programs i.e. HE curricula needed to be changed. Therefore next step was to implement new courses that would prepare school librarians to cope with their users needs and maintain modern school libraries. Only educated and prepared individuals can cope both with the constantly changing information environment and user education.

Changes were implemented on the curricula for our part time students of librarianship mainly due to the fact that these were professionals working mainly in school libraries and they could benefit from this knowledge and implement some of the methods and practices learned. There were two courses offered: Information literacy and E-learning both focusing on the role of school librarian in this still new educational concept. Goal of these cores to give our students insight in the new technology and to educate them on how to implement skills learned in their work environment.

Course on e-learning is offered in two modes: as a distant learning and on site course. The distant learning mode is offered via our e-learning system based on Moodle LMS and in virtual world - Second life. Apart from offering students theoretical background our mission is to provide them with the personal experience of attending such classes. Users who have participated by themselves in usage of new technology in learning and training are able to take into account all the benefits and shortcomings and to introduce new technology and teaching methods in their work environment. As school librarians do have a mission to provide their users with information and insight this is the best mode to do so. 


\section{References}

Al-Fadhli, M. S. Web $2.0+$ Library $=$ Library 2.0 / What is Library 2.0? 2008. http://eprints.rclis.org/12679/1/Web_2.0_\%26_Library_2.0.pdf (17.03.2009.)

Coyle, K. The Library Catalog in a 2.0 World. The Journal of Academic Librarianship. 33(2), 2007. pp. 289291

$\begin{array}{llrrrr}\text { Cohen, } & \text { L. } & \text { A } & \text { Librarians’ } & 2.0 & \text { Manifesto. }\end{array}$ http://liblogs.albany.edu/library20/2006/11/a_librarians_20_manifesto.html (17.03.2009.)

Foo, S., Wee K.W., Ng,Y. (). Library 2.0, Libraries and Library School. 2008. http://www.las.org.sg/pa_sfjn.pdf (17.03.2009.)

Harris, F. J. I found it on the Internet : coming of age online. Chicago: ALA, 2005.

Lepik, A.. Relationship marketing and Library 2.0 : successful prospective partnership?, Signum, 40(5), 2007.pp.13- 16.

Rowley, J, and Hartley. Organizing knowledge. 2008

Stephens, M., Collins, M. Web 2.0, Library 2.0, and the Hyperlinked Library, Serials Review, 33(4), 2007, pp. 253- 256.

Titangos, H.L.H., Mason, G.L. (). Learning Library 2.0: 23 Things @SCPL, Library Management, 30(1/2), 2009, pp. 44- 56.

Freitas, S. Learning in Immersive worlds: A review of game-based learning. JISC, 2006. www.jisc.ac.uk/media/documents/programmes/elearning_innovation/gaming\%20report_v3.3.pdf (17.03.2009.)

Keats, D. Smith, J. P. The genesis and emergence of Education 3.01 in higher education: the potential for Africa. // First Monday. http://www.firstmonday.org/issues/issue12_3/keats/index.html\#author (17.03.2009.)

Kelly, R.V. Massively Multiplayer Online Role-Playing Games: The People, the Addiction and the Playing Experience. McFarland \& Company, August 2004.

Tuominen, K. “Information literacy 2.0”, Signum, 40 (5), 2007, pp. 6-12.

Maness, J. (). "Library 2.0 Theory: Web 2.0 and Its Implications for Libraries". Webology, 3 (2), 2006, http://www.webology.ir/2006/v3n2/a25.html (17.03.2009.)

\section{Statement of Originality}

This statement certifies that the paper above is based upon original research undertaken by the author and that the paper was conceived and written by the author(s) alone and has not been published elsewhere. All information and ideas from others is referenced. 